\title{
Caffeine affects the vigilance decrement of Trite planiceps jumping spiders (Salticidae)
}

Bonnie Humphrey ${ }^{1+}$, William S. Helton ${ }^{2,3}$, Ximena J. Nelson ${ }^{1 *+}$

${ }^{1}$ School of Biological Sciences, University of Canterbury, Private Bag 4800, Christchurch 8140, New Zealand

${ }^{2}$ Department of Psychology, University of Canterbury, Private Bag 4800, Christchurch 8140, New Zealand

${ }^{3}$ Department of Psychology, George Mason University, 4400 University Drive, Fairfax, VA 22030 USA *Correspondence: ximena.nelson@canterbury.ac.nz

${ }^{\dagger}$ Equal authorship

Running head: Caffeine affects jumping spiders

Keywords: visual attention, response decrement, sustained attention, cognitive limitations, salticid

\begin{abstract}
In jumping spiders (Salticidae), the vigilance decrement, or decrease in response to a repeated visual stimulus over time, directly parallels that found in humans. Explanations for the vigilance decrement in the human literature are heavily mentalistic and central nervous system (CNS)-based, whereas response decrements in invertebrates are typically thought of as habituation at the sensory periphery. Here we explored whether the salticid vigilance decrement could be CNS-modulated by using caffeine, which is a well-known CNS stimulant for both vertebrates and invertebrates. We used paired tests in which Trite planiceps Simon spiders were randomly given either a drop of caffeinated water or distilled water and were then shown dot stimuli presented on monitors. We measured both general 'walking', or activity, as a control for physical fatigue, and optomotor responses to the stimuli. We found that the vigilance decrement was significantly shallower (i.e., spiders were more responsive for longer) when spiders were administered caffeine compared with water; furthermore, these spiders were also generally more active throughout the testing period and thus were not physically impaired. Our results suggest that, in at least in some invertebrates, CNS modulation of the vigilance decrement is likely.
\end{abstract}




\section{Introduction}

Caffeine is a central nervous system (CNS) modulator that affects arousal and learning in both vertebrates and invertebrates (Penetar et al., 1993; Alhaider, Aleisa, Tran, Alzoubi, \& Alkadhi, 2010; Mustard, 2014; Nall et al., 2016). Caffeine is a natural product that interacts with the dopamine neurotransmitter signaling pathway in mammals, in which it has been well-studied, via several mechanisms (Fredholm, Bättig, Holmén, Nehlig, \& Zvartau, 1999; Cauli \& Morelli, 2005; Ferré, 2008). Dopamine, known to control voluntary movement and arousal, among other things (Lebestky et al., 2009; Nall et al., 2016), has evolutionarily conserved behavioural roles in invertebrates and vertebrates (Cichewicz et al., 2017). Recent evidence suggests that caffeine interacts with dopamine or analogous pathways in invertebrates (Mustard, 2014; Lebestky et al., 2009; Nall et al., 2016), yet how caffeine affects invertebrates more generally is still unclear, because the vast majority of the work has been done using model systems, such as the fruit fly and honey bees (Mustard, 2014).

Because humans display an inability to maintain signal detection performance with time-ontask, or exhibit a vigilance decrement to repeated stimuli over time, caffeine's effect as a stimulant for sustained attention is widely used to maintain alertness 'on the job'. Sustaining attention is particularly challenging in operational settings that are repetitive, such as being a radar operator, air traffic controller, or in electrocardiogram monitoring, and has thus been well-studied (Mackworth, 1968; Davies \& Parasuraman, 1982; Temple et al., 2000; Helton \& Warm, 2008; Pattyn, Neyt, Henderickx, \& Soetens, 2008; Warm, Matthews, \& Finomore, 2008). Here, for the first time, we explored the effect of caffeine on the vigilance decrement in an invertebrate.

The high load of vigilance and sustained attention (Dukas \& Clark, 1995; Dukas, 2002) on neural processes is likely to be especially acute in animals with small nervous systems (Chan, Giraldo-Perez, Smith, \& Blumstein, 2010; Paulk et al., 2014), like jumping spiders (Salticidae). This may result in animals filtering out irrelevant information from their environment so as to not overload their nervous systems (Itti \& Koch, 2001). If animals are quickly filtering out, and thus ignoring, biologically-irrelevant information, then this should be reflected in a pronounced decay in responses when presented with repetitive stimuli at a constant rate. As visual hunters that are typically less than a centimetre in body size, salticids selectively attend to a wide range of visual stimuli. To do so, they use four pairs of eyes which frame the cephalothorax or head. A forwardfacing pair of principal eyes have a narrow field of view combining outstanding spatial resolution with colour vision (Harland, Li, \& Jackson, 2012). Three pairs of secondary eyes surrounding the cephalothorax have wide fields of view and function primarily as motion detectors encompassing almost $360^{\circ}$ (Duelli, 1978; Land, 1985; Zurek \& Nelson, 2012). Of these, the forward-facing anterior 
lateral $(A L)$ eyes are the largest. Detected motion from one of these secondary eyes may elicit a rapid orienting or optomotor response, whereby the salticid rapidly pivots (swivelling at speeds of c. 700 degrees/second; XJN pers. obs.) to face the object to examine it using the principal eyes, after which it will approach if interested, and in the case of potential prey, slowly stalk it and ultimately pounce (Foelix, 2011), like a minute leopard.

In previous experiments we have explored the vigilance decrement in in the New Zealand salticid Trite planiceps Simon (Humphrey, Helton, Bedoya, Dolev \& Nelson, 2018; Melrose, Nelson, Dolev \& Helton, 2019), finding that when T. planiceps is exposed to repetitive visual stimuli, their optomotor responses to the stimuli rapidly diminish within about the first 10 trials. Previous work demonstrates that $T$. planiceps exhibits some form of response decrement, but the potential mechanisms underlying this decrement are unclear. In particular, our previous work has suggested that the decrement may be centrally-mediated (Humphrey et al., 2018). To further investigate this, here we measured the response decay of $T$. planiceps to repetitive visual stimuli with and without the administration of caffeine using paired testing. As caffeine is a CNS stimulant, we predicted that responses would be higher and last longer in the caffeine treatment if the vigilance decrement was centrally-regulated.

\section{Method}

Detailed methods, including spider housing and maintenance, are described in the electronic supplementary material. Briefly, laboratory-acclimated wild-caught adult and subadult female spiders were tested between $0700-1300$ hours in a temperature-controlled room $\left(25^{\circ} \mathrm{C}\right)$ after a 6 to 8-day period of food deprivation. We ran paired tests in which $T$. planiceps $(N=15)$ were randomly assigned either to a 'water first' or a 'caffeine first' condition.

For caffeine tests, $75 \mathrm{mg}$ of crystalline caffeine (trimethylxanthine), obtained from Sigma Aldrich, was dissolved in $25 \mathrm{ml}$ of distilled water (see electronic supplementary material). Salticids were weighed before dosing so that the amount of solution administered could be weight-adjusted such that each animal received c. $26 \mu \mathrm{g}$ of caffeine per $1 \mathrm{mg}$ of body weight, which is the lowest dosage of caffeine given to spiders in previous studies on web-building (Witt and Reed, 1965; Witt \& Reed, 1965; Witt, Reed \& Peakall 1968; Witt 1971; Hesselberg \& Vollrath, 2004). Salticids were harmlessly restrained with their ventral side facing up within a cylinder that was open at one end, with holes drilled in the opposite, closed, end. Another cylinder, capped with foam onto which a spider was placed, was sized such that when it was plunged into the first cylinder, the spider's mouthparts could be accessed through the holes. Once in position, an Eppendorf Varipette ${ }^{\circledR} 4710$ 
was used to apply a small droplet (mean droplet volume $4.48( \pm 0.22 \mathrm{SEM}) \mu \mathrm{L}, n=32$ ), either of distilled water or of caffeinated water, to the mouthparts, which they readily ingested within 30 min. To ensure that the salticids were ingesting the solution, a paper towel was placed underneath the body to expose any solution trickling past the mouthparts (this never occurred). Once the solution was ingested, salticids were tethered to the apparatus, and given 20 min rest time to settle from handling stress. This also allowed time for the spiders to digest the solution. Methods for the distilled water tests were identical to those described, but instead of a caffeinated solution, only distilled water was given to the spiders.

For testing, spiders were suspended equidistant, at $150 \mathrm{~mm}$, from two identical 17"stimuluspresentation monitors placed at a $120^{\circ}$ angle from each other (Figure 1). The stimulus (Figure 1), which when presented to spiders subtended $1.3^{\circ}$ visual angle, consisted of a low contrast grey circle ( $10 \%$ opacity) moving across a background with random gaussian noise at $40 \%$ (see electronic supplementary material). The stimulus was designed to be solely within the field of view of the AL pair of eyes and moved along the horizon of the spider's field of view (i.e., $0^{\circ}$ vertically), moving laterally to medially, following established methods (Melrose et al., 2019). Stimulus duration was 5 $\mathrm{s}$ with a $10 \mathrm{~s}$ inter-stimulus interval and 80 trials were presented to each spider randomly on either the left or right monitor.

Spiders were tethered in a way that allowed movement of their legs but not whole-body orientations (i.e., head position was fixed). During testing, spiders were given a $17 \mathrm{~mm}$ crosshairmarked polystyrene ball to hold, which was cleaned with $70 \%$ ethanol between tests. Rapid contralateral rotation of the ball indicates an attempted optomotor response: a turn towards the visual stimulus presented to the AL eyes in an attempt to bring the stimulus into the field of view of the principal eyes. Response decay is easily measured, as moving visual stimuli trigger clear optomotor responses, leading to a fast swivel of the polystyrene ball. Each test was recorded by a Logitech $^{\circledR}$ webcam placed above and behind the spider. Recorded video was viewed on a monitor located near the testing apparatus, but separated by a black curtain. The experimenter scored responses in real-time, based on interpretation of the spiders' movements, which were recorded as categorical variables; these being: 0 for 'no movement', 1 for general walking or 'activity', which was recorded to control for the possibility that any response decrement observed was due to physical fatigue, and 2 as 'interest', or rapid orientations towards the stimulus. Each movement category is distinct from one other and cannot be performed in unison (i.e., a spider can not walk and perform an optomotor response simultaneously). Responses are thus easy to define, as 
confirmed by a Cronbach's alpha score of 0.95 obtained between two blind scorers (see electronic supplementary material for more information).

Data were analysed in R v.3.3.1, using a cumulative link mixed-effect model which accounted for individual spider differences through random effects. We used model selection based on the Akaike Information Criterion to determine an appropriate fixed-effects structure. For visualisation, we omitted the no movement category and fitted the remaining data in MatLab version 2015a with an exponential function $f(t)=\alpha e^{\lambda t}$ over all trials, as this is the best fit for these data (Humphrey, et al., 2018). Here, $\lambda$ is the decay rate, $\alpha$ is the initial quantity of the response, and $t$ is the current trial.

\section{Results}

In both treatments, salticids showed a decline in responses to the repetitive visual stimuli across trials, but the decrement in response was much steeper in the control treatment (Figure 2). The decay rate for the interest category in the caffeine treatment was -0.0217 (confidence intervals, $\mathrm{Cl}$, $-0.0273,-0.0161)$ and that of distilled water was $-0.1202(\mathrm{Cl},-0.1581,-0.0823)$. The decay rate for the activity category in the caffeine treatment was $0.0065(\mathrm{Cl}, 0.0026,0.0103)$ and that of water was $-0.0074(\mathrm{Cl},-0.0128,-0.002)$.

Caffeine had a strong effect in that $T$. planiceps maintained their responses to the stimulus for longer (Table 1). Trite planiceps was more likely to initially respond in an 'interest' response category when given caffeine compared to water and remained more responsive over the duration of the trials when given caffeine, revealing a significantly slower response decrement when they were given the CNS stimulant. General movement remained constant throughout trials with water, suggesting that any observed decrement was not due to physical fatigue. This was also true in trials when spiders were given caffeine, with the only apparent difference being that, in these trials, general movement increased slightly over time (Figure 2), corroborating the notion that physical fatigue is unlikely to account for these results.

\section{Discussion}

Behaviours that are controlled by the peripheral nervous system, such as sensory habituation, are believed to be simpler than behaviours under CNS control (Bernardo, Stone, \& Koopowitz, 1977). Appropriately, the first behavioural account of habituation described how web-spiders moved smaller and smaller distances along their webs in response to the repeated sound of a tuning fork (Peckham \& Peckham, 1887). Our findings on a visually-based task, coupled with previous work 
(Humphrey et al., 2018; Nelson, Helton, \& Melrose, 2019), support the hypothesis that the response decrement in salticid spiders is centrally-regulated. We found that salticids showed a markedly reduced vigilance decrement when given caffeine as opposed to water, indicating that they remained responsive to the visual stimuli for longer with caffeine. Because caffeine is a CNS stimulant, this suggests that the response decrement is likely controlled by the CNS, as opposed to being entirely mediated by the peripheral nervous system. However, this is not conclusive, as we did not investigate the role of neurotransmitters, such as dopamine, in this study.

In Drosophila melanogaster, caffeine is known to promote wakefulness through presynaptic effects on dopaminergic receptors in the brain, resulting in increased dopamine release (Nall et al., 2016). However, whether caffeine affects salticid behaviour through performance and/or competence factors is not yet known. Previous studies (Witt \& Reed, 1965; Witt, Reed \& Peakall, 1968; Witt, 1971; Hesselberg \& Vollrath, 2004) have shown that the effects of drugs in spiders are analogous to their effects in humans, so we can assume that caffeine has a similar effect on $T$. planiceps as it does humans (i.e., increased alertness, focus and improved motor functions). These physiological effects were reflected in our results through the higher level of general activity and a more gradual response decrement. Perhaps the spiders were more alert so 'picked up' on more stimuli, or maybe they had more energy and more motivation to actively respond, as opposed to sitting still or grooming. Nevertheless, as this is the first study on the effects of caffeine on salticids we cannot conclude what may be happening on a physiological level, and more research to elucidate the precise pathways is required.

The attenuation of the crayfish tail flexion reflex in response to repeated tactile stimulation is a classic example of peripheral habituation (Araki \& Nagayama, 2005; Nagayama \& Araki, 2015), and it has been shown that, when extracted from the crayfish, the lateral giant interneuron mediating the behaviour habituates by reducing its excitability (Nagayama \& Araki, 2015). Response decrements through habituation to an irrelevant stimulus are a widespread phenomenon, having also been demonstrated in the 'simplest' of organisms, including in slime moulds (Boisseau, Vogel, \& Dussutour, 2016). Nevertheless, many studies do not actually test whether invertebrate decrements are peripherally-mediated (and thus largely sensory habituation). Instead, they simply assume that the response decrements are not centrally-mediated because the habituation literature predicts, for example, that when given a new stimulus, a habituated response should dishabituate, which seemingly it does in bumblebees (e.g., Plowright, Simonds, \& Butler, 2006), but not in salticids (Melrose et al., 2019). 
It may be naive to assume that the mechanism underlying the vigilance decrement, either in mammals or in invertebrates, is strictly either in the sensory periphery or the CNS. The decrement is bound to be a product of phenomena occurring in both systems, such as reduced excitability of visual sensory cells, and altered activity in the brain, possibly due to an inability to selectively attend to information because of overstimulation. In fact, the nature of the abovementioned crayfish response itself highlights this: the interneuron is a CNS cell, but it is responding directly to the sensory afferent information provided to it, demonstrating the inextricably interrelated nature of these phenomena. Perhaps the question that needs further investigation is the exact relationship between how much processing occurs peripherally versus centrally in different taxa, and if this bears any relationship with central neural processing capacity, as this is by no means a clear relationship (e.g., Chittka \& Niven, 2009; Perry \& Chittka, 2019).

Human studies seem to be reaching a consensus (e.g., Temple et al., 2000; Helton \& Warm, 2008; Warm et al., 2008; Patterson, Lochtefeld, Larson, \& Christensen-Salem, 2019) that the vigilance decrement is largely due to the high neural or cognitive processing load required in the CNS (rather than the opposite hypothesis, which postulates that the human brain is understimulated with repetitive stimuli, leading to loss of concentration; Pattyn et al., 2008). It would therefore seem logical to extrapolate that the vastly more neuronally-challenged brains of salticids would face the same effects, just significantly more intensely. Oddly, data generally do not support this notion (Chittka \& Niven, 2009; Perry \& Chittka, 2019). In vigilance tasks, salticids tend to be overall less responsive then humans, but show the same tendencies (Melrose et al., 2019; Nelson et al., 2019), and several studies have attested that despite their small brains, salticids are capable of remarkable feats of learning (Leidtke \& Schneider, 2014; De Agrò, Regolin, \& Moretto, 2017), and possibly even planning (Tarsitano \& Andrew, 1999; Nelson \& Jackson, 2011), while web-building spiders show no evidence of limitations on their web-construction with miniaturization (Eberhard, 2011). Our results corroborate recent lines of evidence that suggest that relatively high-level cognitive phenomena need not require large brains.

\section{Ethics}

All work complied with the laws of New Zealand and international and APA ethical standards.

\section{Data accessibility}

Data are included as electronic supplementary material.

\section{Authors' contributions}


B.H., W.H. and X.N. conceptualised the study, X.N. wrote the paper, and B.H. carried out the experiments and analysed the data. All authors approved the final version and agree to be accountable for the work.

\section{Competing interests}

The authors declare no competing interests.

\section{Funding}

This research did not receive any specific grant from funding agencies in the public, commercial, or not-for-profit sectors.

\section{Acknowledgments}

We are grateful to Aynsley McNab and Matt Walters, who provided technical assistance; Averill Moser helped with blind scoring; Yinnon Dolev helped prepare the stimuli; Daniel Gerhard provided statistical advice; and Carol Bedoya prepared Figure $2 \mathrm{~b}$. 


\section{References}

Alhaider, I. A., Aleisa, A. M., Tran, T. T., Alzoubi, K. H., \& Alkadhi, K. A. (2010). Chronic caffeine treatment prevents sleep deprivation-induced impairment of cognitive function and synaptic plasticity. Sleep, 33, 437-444. doi:10.1093/sleep/33.4.437

Araki, M., \& Nagayama, T. (2005). Decrease in excitability of LG following habituation of the crayfish escape reaction. Journal of Comparative Physiology A, 191, 481-489. doi:10.1007/s00359-0050607-y

Bernardo, K., Stone, G.C., \& Koopowitz, H. (1977). Primitive nervous systems: peripheral habituation in decerebrate polyclad flatworms. Journal of Neurobiology, 8, 141-150. doi: $10.1002 /$ neu.480080206

Boisseau, R. P., Vogel, D., \& Dussutour, A. (2016). Habituation in non-neural organisms: evidence from slime moulds. Proceedings of the Royal Society Lond B 283. 10.1098/rspb.2016.0446

Cauli, O., \& Morelli, M. (2005). Caffeine and the dopaminergic system. Behavioural Pharmacology $16,63-77$.

Chan, AAY-H., Giraldo-Perez, P., Smith, S., \& Blumstein, D. T. (2010). Anthropogenic noise affects risk assessment and attention: the distracted prey hypothesis. Biology Letters, 6, 458-461 doi:10.1098/rsbl.2009.1081

Chittka, L., \& Niven, J. (2009). Are bigger brains better? Current Biology, 19, R995-R1008. doi:10.1016/j.cub.2009.08.023

Cichewicz, K., Garren, E. J., Adiele, C., Aso, Y., Wang, Z., Wu, M., Birman, S., Rubin, G. M., \& Hirsh, J. (2017). A new brain dopamine-deficient Drosophila and its pharmacological and genetic rescue. Genes Brain and Behavior, 16, 394-403. doi:10.1111/gbb.12353

Davies, D. R., \& Parasuraman, R. (1982) The psychology of vigilance. Academic Press: London.

De Agrò, M., Regolin, L., \& Moretto, E. (2017). Visual discrimination learning in the jumping spider Phidippus regius. Animal Behavior and Cognition, 4, 413-424.

doi:10.26451/abc/.04.04.02.2017

Duelli, P. (1978). Movement detection in the posterolateral eyes of jumping spiders (Evarcha arcuata, Salticidae). Journal of Comparative Physiology, 124, 15-26.

Dukas, R. (2002). Behavioural and ecological consequences of limited attention. Philosophical Transactions of the Royal Society Lond, 357, 1539-1547. doi:10.1098/rstb.2002.1063

Dukas, R., \& Clark, C. W. (1995). Sustained vigliance and animal performance. Animal Behaviour, 49, 1259-1267. 
Eberhard, W. G. (2011). Are smaller animals behaviorally limited? Lack of clear constraints in miniature spiders. Animal Behaviour, 81, 813-823. doi:10.1016/j.anbehav.2011.01.016

Ferré, S. (2008). An update on the mechanisms of the psychostimulant effects of caffeine. Journal of Neurochemistry, 105, 1067-1079. doi:10.1111/j.1471-4159.2007.05196.x

Foelix, R. F. (2011). Biology of Spiders. Third ed. New York: Oxford University Press.

Fredholm, B. B., Bättig, K., Holmén, J., Nehlig, A., \& Zvartau, E. E. (1999). Actions of caffeine in the brain with special reference to factors that contribute to its widespread use. Pharmacological Reviews, 51, 83-133.

Harland, D. P., Li, D. \& Jackson, R. R. (2012). How jumping spiders see the world. In O. F. Lazareva, T. Shimizu \& E. A. Wasserman (Eds.), How Animals See the World: Comparative Behavior, Biology, and Evolution of Vision (pp. 133-164). New York: Oxford University Press.

Helton, W. S., \& Warm, J. S. (2008). Signal salience and the mindlessness theory of vigilance. Acta Psychologica, 129, 18-25. doi:10.1016/j.actpsy.2008.04.002

Hesselberg, T., \& Vollrath, F. (2004). The effects of neurotoxins on web-geometry and web building behaviour in Araneus diadematus Cl. Physiology \& Behavior, 82, 519-229. doi:10.1016/j.physbeh.2004.04.058

Humphrey, B., Helton, W. S., Bedoya, C., Dolev, Y., \& Nelson, X. J. (2018). Psychophysical investigation of vigilance decrement in jumping spiders: Overstimulation or understimulation? Animal Cognition, 21, 787-794. doi:10.1007/s10071-018-1210-2

Itti, L., \& Koch, C. (2001). Computational modelling of visual attention. Nature Reviews Neuroscience, 2, 194-203. doi:10.1038/35058500

Land, M. F. (1985). Fields of view of the eyes of primitive jumping spiders. Journal of Experimental Biology, 119, 381-384.

Lebestky, T. J., Chang, J-SC., Dankert, H., Zelnik, L., Kim, Y-C., Han, K-A., Perona, P., \& Anderson, D. J. (2009). Two different forms of arousal in Drosophila are independently and oppositely regulated by the dopamine D1 receptor DopR via distinct neural circuits. Neuron, 64, 522-536. doi:10.1016/j.neuron.2009.09.031

Leidtke, J., \& Schneider, J. M. (2014). Association and reversal learning abilities in a jumping spider. Behavioural Processes, 103, 192-198. doi:10.1016/j.beproc.2013.12.015

Mackworth, J. F. (1968). Vigilance, arousal, and habituation. Psychological Review, 75, 308-322. doi:10.1037/h0025896 
Melrose, A., Nelson, X. J., Dolev, Y., \& Helton, W. S. (2019). Vigilance all the way down: Vigilance decrement in jumping spiders resembles that of humans. Quarterly Journal of Experimental Psychology, 72, 1530-1538. doi:10.1177/1747021818798743

Nelson, X. J., \& Jackson, R. R. (2011). Flexibility in the foraging strategies of spiders. In M. E. Herberstein (Ed.), Spider behaviour: Flexibility and versatility (pp. 31-56). New York: Cambridge University Press.

Nelson, X. J. Helton, W. S., \& Melrose, A. (2019). The effect of stimulus encounter rate on response decrement in jumping spiders. Behavioural Processes, 159, 57-59. doi: 10.1016/j.beproc.2018.12.020

Mustard, J. A. (2014). The buzz on caffeine in invertebrates: effects on behavior and molecular mechanisms. Cellular and Molecular Life Sciences, 71, 1375-1382. doi:10.1007/s00018-0131497-8

Nagayama, T., \& Araki, M. (2015). Habituation of LG-mediated tailflip in the crayfish. Invertebrate Neuroscience, 15, 178. doi:10.1007/s10158-015-0178-8

Nall, A. H., Shakhmantsir, I., Cichewicz, K., Birman, S., Hirsh, J., \& Sehgal, A. (2016). Caffeine promotes wakefulness via dopamine signaling in Drosophila. Scientific Reports, 6, 20938. doi:10.1038/srep20938

Paulk, A. C., Stacey, J. A., Pearson, T. W. J., Taylor, G. J., Moore, R. J. D., Srinivasan, M. V., \& van Swinderen, B. (2014). Selective attention in the honeybee optic lobes precedes behavioural choices. Proceedings of the National Academy of Sciences, USA, 111, 5006-5011. doi:10.1073/pnas.1323297111

Patterson, R. E., Lochtefeld, D., Larson, K. G., \& Christensen-Salem, S. In Press. Computational modeling of the effects of sleep deprivation on the vigilance decrement. Human Factors. doi:10.1177/0018720819829949

Pattyn, N., Neyt, X., Henderickx, D., \& Soetens, E. (2008). Psychophysiological investigation of vigilance decrement: boredom or cognitive fatigue? Physiolgy \& Behavior, 93, 369-378. doi:10.1016/j.physbeh.2007.09.016

Peckham, G. W., \& Peckham, E. G. (1887). Some observations on the mental powers of spiders. Journal of Morphology, 1, 383-419.

Penetar, D., McCann, U., Thorne, D., Kamimori, G., Galinski, C., Sing, H., Thomas, M. L., \& Belenky, G. (1993). Caffeine reversal of sleep deprivation effects on alertness and mood. Psychopharmacology, 112, 359-365. 
Perry, C. J., \& Chittka, L. (2019). How foresight might support the behavioral flexibility of arthropods. Current Opinion in Neurobiology, 54, 171-177. doi:10.1016/j.conb.2018.10.014

Plowright, C. M. S., Simonds, V. M., \& Butler, M. A. (2006). How bumblebees first find flowers: habituation of visual pattern preferences, spontaneous recovery, and dishabituation. Learning and Motivation, 37, 66-78. doi:10.1016/j.Imot.2005.03.002

Tarsitano, M. S. \& Andrew, R. (1999). Scanning and route selection in the jumping spider Portia labiata. Animal Behaviour, 58, 255-265. doi:10.1006/anbe.1999.1138

Temple, J. G., Warm, J. S., Dember, W. N., Jones, K. S., LaGrange, C. M., \& Matthews, G. (2000). The effects of signal salience and caffeine on performance, workload and stress in an abbreviated vigilance task. Human Factors, 42, 183-194. doi:10.1518/001872000779656480

Warm, J. S., Matthews, G., \& Finomore, Jr V. S. (2008). Vigilance, workload, and stress. In P. A. Hancock \& J. L. Szalma (Eds.), Performance under stress (pp. 115-141). Burlington, VT: Ashgate Publishing Company.

Witt, P. N. (1971). Drugs alter web-building of spiders: A review and evaluation. Behavioural Science, $16,98-113$.

Witt, P. N., \& Reed, C. F. (1965). Spider-web building. Science, 149, 1190-1197.

Witt, P. N., Reed, C. F. \& Peakall, D. B. (1968). A spider's web: Problems in regulatory biology. New York: Springer-Verlag.

Zurek, D. B., \& Nelson, X. J. (2012). Hyperacute motion detection by the lateral eyes of jumping spiders. Vision Research, 66, 26-30. doi:10.1016/j.visres.2012.06.011 
(a)

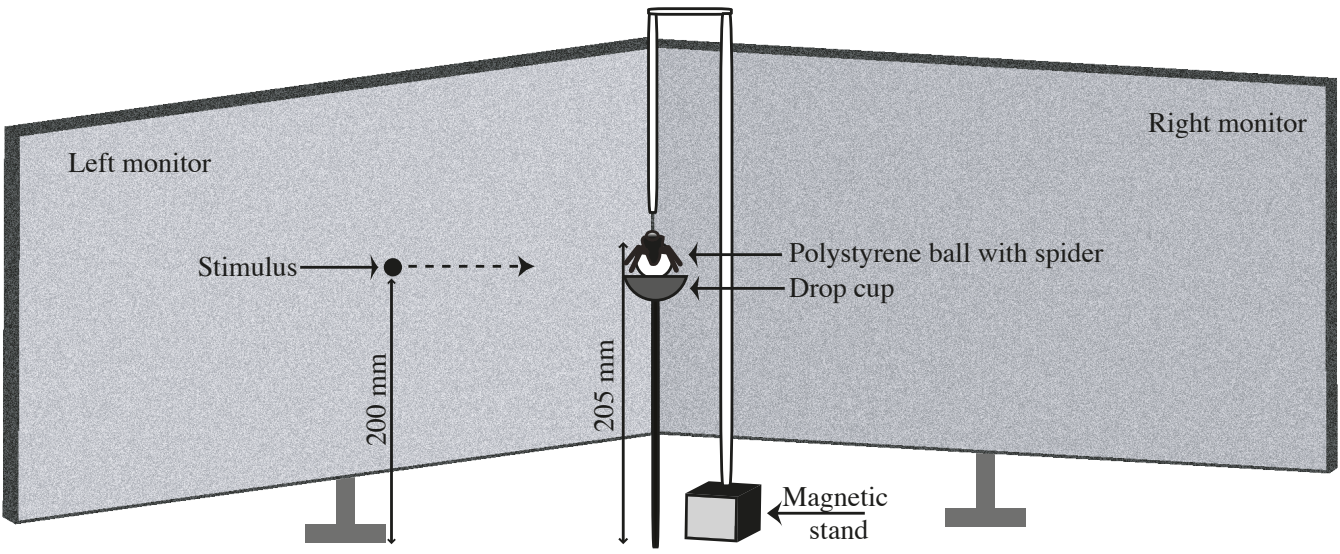

(b)

Figure 1. a) Apparatus used for testing Trite planiceps depicting spider holding the polystyrene ball. Drop cup catches balls dropped during testing. b) Stimulus used in experiments. Low contrast (10\% opacity) dot stimulus against noise (40\%). 

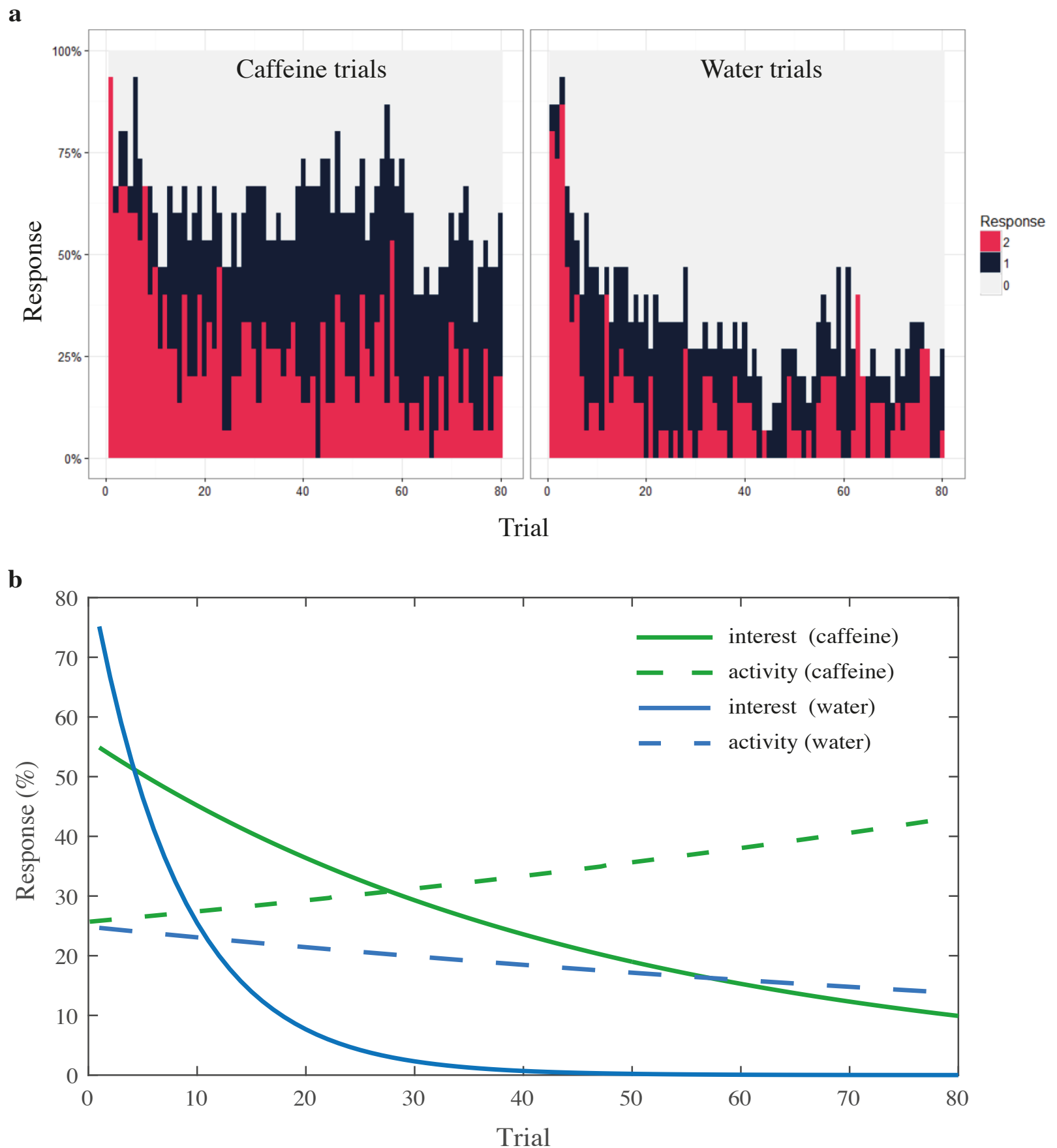

Figure 2. a) Raw data depicting responses of Trite planiceps spiders to visual stimuli. Spiders received a caffeine droplet and distilled water droplet before being shown a repetitive dot stimulus ( 80 trials). Behaviours were recorded as: no movement (0); general activity, such as walking on the ball (1), and interest, or attempts to orient toward the stimulus (2). b) Response decay rate (DR) fitted as an exponential function over the 80 trials. Green lines: responses when given caffeine. Blue lines: responses when given water. Solid lines: visual (optomotor) responses to dot stimuli ('interest'). Dotted lines: general movement ('activity'). 
Table 1. Model-selection results for the significance of treatment (caffeine or water) on responses to a repetitive visual stimulus in Trite planiceps. K: number of estimated parameters for each model; AICc: Akaike's Information Criterion; $\triangle$ AICc: the appropriate delta AIC component. AICcW: Akaike weights. Fixed effects (trial, T, caffeine treatment, C) and pairwise interactions*.

\begin{tabular}{llllll}
\hline Effects & Model & K & AICc & A AICc & AICcW \\
\hline Caffeine treatment & $(\mathrm{T}+\mathrm{C})^{*}$ & 9 & 4328.12 & 0.00 & 1 \\
Trial only & $\mathrm{T}$ & 7 & 4553.56 & 225.43 & 0 \\
\hline
\end{tabular}




\section{Electronic supplementary material}

\section{Methods}

\section{Maintenance and testing methods}

Laboratory lighting was on a 12:12 L:D cycle commencing at $0700 \mathrm{~h}$. Temperature was kept constant at $25^{\circ} \mathrm{C}$. Adult Trite planiceps were housed in upside down transparent plastic jars $(17 \mathrm{~cm}$ tall $\times 8$ $\mathrm{cm}$ wide) with a cotton roll inserted through the lid into a cup of water to ensure constant humidity. Two holes were drilled into the opposite end of the jar; one covered with mesh for ventilation and the other plugged with a cork that could be removed to insert houseflies (Musca domestica) or Drosophila as food. Each spider was fed once per week immediately after testing. Housing jars were cleaned weekly. Inside the jar was a folded piece of card providing envonmental enrichment in which $T$. planiceps could hide and build nests.

The testing apparatus was placed on a vibration isolation platform. It consisted of a holding stand, a Logitech ${ }^{\circledR}$ webcam, and two identical monitors placed at a $120^{\circ}$ angle relative to each other. The monitor screens were 17' Phillips Brilliance 170P $1280 \times 1042$ with a refresh rate of $75 \mathrm{~Hz}$. They were standardised for brightness and colour using Spyder 4 Pro ${ }^{\circledR}$ colorimeter and accompanying software.

These tests consisted of a low contrast 'signal' (stimulus circle) of 10\% opacity (RGB 239, 239, 239) moving across a moderately 'noisy' screen. Noise was generated using Adobe Photoshop ${ }^{\circledR}$ CS6 and was added as a foreground image, with the moving stimulus set as the background layer. The stimulus and noise were later exported into Adobe Premiere ${ }^{\circledR}$ CS6 Motion Effects to generate a unique movie file with an output set to the combined size of both monitors and which had a grey background (RBG 250, 250, 250). To generate noise, the noise filter in Photoshop was used to assign random pixels to the image. We used a Gaussian distribution and monochromatic colour mode to create noise at $40 \%$ [see 1 for full details]. To generate the stimulus, Adobe Premiere ${ }^{\circledR}$ was configured to display media at the screen size of the apparatus (i.e., 2560 x 1042 pixels, which was the combined size of the two monitors), and a full stop was enlarged to 40 pixels, with opacity set at 10\% (RGB 239, 239, 239). Two files were generated, one for each (left and right) screen. Stimuli were designed to be within the field of view of the AL eyes only and moved along the horizon of the spider's field of view (i.e., $0^{\circ}$ vertically), moving from posterior to anterior. Preliminary tests determined that stimuli needed to appear within $8-16 \mathrm{~cm}(321-640$ pixels $)$ from the centre (midpoint) of the monitor to coincide with the field of view of the AL eyes of $T$. planiceps [1]. We generated stimuli that moved on screen from $13 \mathrm{~cm}$ to $8 \mathrm{~cm}$. Once it reached the $8 \mathrm{~cm}$ mark, the stimulus was set to change to $0 \%$ opacity (effectively disappearing) and continued moving at $0 \%$ opacity for $10 \mathrm{~s}$ to create the inter-stimulus interval (ISI). This generated a $15 \mathrm{~s}$ video with the stimulus 
moving for $5 \mathrm{~s}$ with a $10 \mathrm{~s}$ ISI. Each test consisted of 80 stimulus trials per salticid. Stimuli were presented randomly on either the left or right screen, as there is no side bias in responses [2].

Before testing, salticids were placed inside the 'gunkatron'. This was composed of a cylinder that was open at one end, with holes drilled in the opposite, closed, end. Another cylinder, capped with foam onto which a spider was placed, was sized such that when it was plunged into the first cylinder, the spider's cephalothorax could be accessed through the holes. This permitted us to harmlessly restrain each spider. Once in position, the spider was fixed to a TPC® disposable microapplicator by applying beeswax to the top of the cephalothorax, so that the legs of each spider were mobile but their heads remained fixed. The applicator with the spider attached was then suspended within the testing apparatus by a crocodile clip. The spider was given a $17 \mathrm{~mm}$ crosshair marked polystyrene ball (weight $150 \mathrm{mg}$ ) to hold, which is easily held by these spiders [2]. Within the rig, 10 mm underneath the polystyrene ball was a small concave 'cup' which served to catch the ball in case the spider dropped the ball. The ball was cleaned with $70 \%$ ethanol after each spider was tested to remove any chemicals deposited by previous individuals.

\section{Preliminary tests for caffeine administration}

Preliminary tests were conducted to determine the best method of drug administration and dosage. To reduce the number of confounding variables, administration of sugar within the caffeine solution and depriving animals of water prior to experimentation (as used in experiments with web-building spiders; $[3,4,5])$, were avoided, as the salticids drank the solution regardless of thirst or sweetness.

\section{Reliability testing}

Two people (BH and a volunteer, AM) did blind scoring of 24 trials for each condition. Scores were compared and resulted in a 95\% correlation between the two experimenters (Cronbach's alpha $=$ 0.952). BH is very experienced at coding (having coded thousands of trials) these types of tests and AM had never coded these types of tests before.

\section{References}

1. Humphrey B, Helton WS, Bedoya C, Dolev Y, Nelson XJ. 2018 Psychophysical investigation of vigilance decrement in jumping spiders: Overstimulation or understimulation? Anim. Cogn. 21, 787-794. (doi:org/10.1007/s10071-018-1210-2)

2. Melrose A, Nelson XJ, Dolev Y, Helton WS. 2019 Vigilance all the way down: Vigilance decrement in jumping spiders resembles that of humans. Q. J. Exp. Psychol. (doi: $10.1177 / 1747021818798743$ ) 
3. Witt PN. 1971 Drugs alter web-building of spiders: A review and evaluation. Behav. Sci. 16, 98113. (doi:https://doi.org/10.1002/bs.3830160109)

4. Samu F, Vollrath F. 1992 Spider orb web as bioassay for pesticide side effects. Entomol. Exp. Appl. 62, 117-124. (doi:https://doi.org/10.1111/j.1570-7458.1992.tb00650.x)

5. Hesselberg T, Vollrath F. 2004 The effects of neurotoxins on web-geometry and web building behaviour in Araneus diadematus CI. Physiol. Behav. 82, 519-229. (doi:10.1016/j.physbeh.2004.04.058) 